\title{
Inter-language Fossilization and Teaching Strategies
}

\author{
Shuo Yang \\ School of Foreign Languages,Jinlin Business and Technology College,ChangChun,130507
}

Key words: inter-language; fossilization; teaching strategies

\begin{abstract}
Inter-language fossilization is common in the process of foreign language learning, which causes foreign language learners not to make progress any more. Adjusting teaching strategies by improving teachers' ability, reforming teaching and evaluation methods and creating learning context is beneficial to break down the rigid state of language learning and improve the level of foreign language teaching in China.
\end{abstract}

\section{Introduction}

In the process of teaching and learning a foreign language, there is a phenomenon: after a certain level of foreign language is reached, a plateau will occur. In this plateau, the foreign language level is not rapidly improved as before, but is at a standstill or even setback. The foreign language can not be used as smoothly as the mother language. After years of learning, both in daily conversation and in writing, some refractory permanent mistakes are still frequently made ${ }^{[1]}$. These refractory permanent mistakes are called interlanguage fossilization.

\section{Interlanguage and Fossilization}

Before fossilization is introduced, interlanguage is first discussed. Interlanguage is a language system between the mother language and the target language ${ }^{[2]}$. This language system closely connects the mother language with the target language, featuring the characteristics of both the mother language and the target language. In the process of learning, the interlanguage becomes more and more similar to the target language, but will not ultimately be the target language. The term interlanguage was brought forward by Slinker at the Cambridge International Conference in 1969, so was its transitional, systematic, permeable and open characteristics.

Fossilization can be construed as the tendency to permanence of some non-standard or even incorrect language items, grammar and systematic knowledge of the interlanguage which are unchanged along with the improvement of foreign language level and the increase of learning time. Fossilization is often latent, and occurs unconsciously in the interlanguage. Fossilization has two types which are individual fossilization and popular fossilization. The former refers to the permanence of interlanguage of an individual person, while the latter to that of the entire society.

The fossilization of interlanguage can be temporary or permanent. Researches have shown that temporary fossilization tends to happen to non-English majors. With appropriate measures, the temporary fossilization can be completely eliminated, and thereby the foreign language learner' $\mathrm{s}$ level will be improved. Hence, the researches on the elimination of temporary fossilization are very necessary and of great significance to China’ s foreign language teaching.

\section{Causes of Interlanguage Fossilization}

Interlanguage fossilization is caused by many factors, and can come into shape as a result of a small deviation in the foreign language learning process ${ }^{[3-6]}$. Summarized on the basis of years of teaching experience, the causes of interlanguage fossilization can be briefly classified into internal factor and external factor.

A.Internal Factors

1)Age of the foreign language learner

Generally, the plasticity of the brain of a foreign language learner decreases along with his aging. Researches have shown that the age from 12 to 15 is a critical period for human language 
acquisition. Before this critical period, the interlanguage fossilization hardly occurs, and the learning of target language is relatively easy. Nevertheless, after the critical period, interlanguage fossilization may occur, embodied in the inability of foreign language learner to exactly grasp the target language' s characteristics. However, it is not that the learners are unable to acquire a target language after the critical period, but it is just easier for them to do so before the critical period.

2)Purpose of the foreign language learners

Generally, the purposes of the foreign language learners can be classified into comprehensive purpose and instrumental purpose. The comprehensive purpose means that the learners learn the foreign language for the purpose of communication. These learners tend to regard highly the cultural and historical background of the target language, and study hard and long with a strong interest. The instrumental purpose means that the purpose of learning is to pass the examination. These learners tend to care only about the examination, and not about the use of the language to communicate. Once they pass the examination, they will lose their motivation for further learning. This short-term way of learning is prone to cause interlanguage fossilization.

3)Mentality of the foreign language learner

The mental changes in the learning process of the foreign language learners take crucial effect. For instance, when just beginning to learn a foreign language, the learners are always enthusiastic and have a strong interest, so they improve fast. When they reach a certain level and encounter bottlenecks, the learners will feel anxious about the setback in the learning state, and thus lose their interest and motivation. If the foreign language learner cannot adjust their mentality at this time, the interlanguage fossilization may probably occur.

4)Method of the foreign language learner

The foreign language learners must adjust their learning methods, based on various problems encountered in the learning process. An efficient learning method that is fit for a learner can accelerate the acquisition of a foreign language. Learning by rote is prone to cause interlanguage fossilization.

\section{B.External factors}

1)Influence of target language culture on the foreign language learner

In order to acquire a foreign language, the cultural background of that language in related countries must be known. Cultural differences may result in different understanding of the same thing. If the foreign language learner cannot understand or accept this difference in the heart, they will be resistant to that language. This resistant feeling will directly result in the difficulty of the foreign language learner to improve their level. If this situation continues, the interlanguage fossilization will occur.

2)Influence of communicative feedback on the foreign language learner

In the process of learning foreign language, the learners communicate with the external world through writing and talking. Mistakes inevitably occur during the use of interlanguage, and some of the mistakes do no harm to the understanding between the communicators. If the communicators do not provide feedbacks on these mistakes, the foreign language learners won' $t$ specifically and deliberately correct their interlanguage. Gradually, the interlanguage fossilization will occur. Moreover, intemperate feedback on the mistakes in interlanguage is inadvisable, because it will injure the learner' $s$ self-confidence, and deprive their motivation in the improvement of interlanguage.

3)Influence of teachers on the foreign language learner

The teacher' s knowledge level and teaching method directly affects the foreign language learner' s learning outcome. The teacher must have extensive and accurate knowledge. Once the teacher imparts some incorrect knowledge to the foreign language learner, the incorrect knowledge will solidify in the learner' $s$ mind, and result in interlanguage fossilization. Improper teaching method also affects the foreign language learner' s enthusiasm. 


\section{Teaching Strategy to overcome the interlanguage fossilization}

Teaching is an important link to help the foreign language learners to overcome the interlanguage fossilization. Based on years of teaching experience and on the internal and external factors to cause interlanguage fossilization, some teaching strategies are specified in order to overcome the interlanguage fossilization.

A. Promotion of the teacher' s ability

Since the teacher is the source of knowledge for the foreign language learners, the ability of the teacher plays a crucial role in the learning of foreign language. The ability includes the ability of foreign language knowledge and the ability to perceive the learner' s psychological changes and to effectively evaluate the changes. The ability of foreign language knowledge manifests in the extensiveness and correctness of the teacher' s professional knowledge. Only with extensive professional knowledge, can the teacher extensively communicate with the foreign language learners, furthest promote the learners' learning interest and stimulate the learners' admiration for the cultural background of the related foreign countries. Accurate professional knowledge helps the foreign language learners immediately grasp the important and difficult points, improve listening, speaking, reading and writing abilities in all round, and keep forward in the right direction. The teacher must timely perceive the learner' $s$ mental changes in the learning process, properly encourage or criticize them, strengthen their confidence, and consolidate their bravery and determination in face of difficulties. The teachers must constantly improve their own professional ability and the ability to perceive the learners' metal changes, in order to effectively help the foreign language learners to overcome the interlanguage fossilization.

\section{B. Improvement of teaching method}

The improvement of teaching method takes great effect on overcoming the interlanguage fossilization. Traditional teaching method is relatively monotonic. Nearly cramming system makes the classes vapid and dull. Repeated high-intensity exercises make the foreign language learners feel bored with the learning process, and lose their learning interest and initiative. Therefore, the existing teaching method must be properly improved. The teaching method must be adjusted to make the classroom full of variety. Various teaching tools must be utilized. With the foreign language learners participating in various activities, their sense of freshness is increased and their learning interest in the foreign language is maintained.

\section{Reformation of evaluation method}

Currently, China' s evaluation method for foreign language is limited to examination, and the examination result is the only criterion to evaluate the learner' s level of foreign language. In this way, the foreign language learners tend to attach importance to the test-taking skills, and ignore the daily communicative need, which often results in high score and low ability. Gradually, language fossilization occurs. Thus, the reformation of evaluation method for foreign language learning is imperative. The reformation will not abolish exams, but will improve exams. Basic communicative skills, such as listening, speaking, reading and writing should all be integrated into the examination. In the exam, not only the writing ability, but also the ability to actually communicate in daily conversations should be tested. With the testing method innovated, the evaluation will more comprehensively reflect the learner' $s$ level of foreign language, and the stagnation of comprehensive abilities due to too much emphasis on one certain ability will be avoided.

\section{D.Creation of learning atmosphere}

Most foreign language learners barely encounter foreign language environment outside the classroom, so that the input of the foreign language is insufficient. If the input insufficiency of foreign language is normalized, interlanguage fossilization will occur. In order to increase the input of foreign language, it is very important to create an atmosphere for learning foreign language outside the classroom, besides the improvement of classroom efficiency. The creation of atmosphere for foreign language learning outside the classroom involves after-class tutoring, speech 
contest, writing contest, and cultural communication activities with foreigners. The foreign language atmosphere can effectively inhibit the stagnation or even degeneration of foreign language ability due to the insufficiency of language input.

\section{Conclusion}

Interlanguage fossilization in foreign language learning is inevitable. The careful analysis of its causes and the specific adjustment of teaching strategies can effectively help the foreign language learners overcome the effect of interlanguage fossilization on professional knowledge and on psychological level, and rapidly and stably promote their language level.

\section{References}

[1] YANG Lianrui, YIN Hongshan, ZHAO Changzhi et al. Progress in Researches on Interlanguage Fossilization. Foreign Languages and Their Teaching [J]. 2014.01:36-40

[2] WU Ding'e. Interlanguage and Its Fossilization in the Acquisition of Second Language. Foreign Language Teaching [J]. 2001.02:17-22

[3] LI XIaolan, XIAO Xi. Causes of Fossilization in the Acquisition of Second Language. Overseas English [J]. 2012.02:7-8

[4] WANG Zhen. Cause Analysis of Interlanguage Fossilization and Revelations on Teaching. Reading and Writing [J]. 2011.02:38-39

[5] LI Shaopeng, YANG Lianrui. Research on Topic Prominence of Chinese-English Interlanguage from the Perspective of Discourse. Foreign Languages [J]. 2013.06:63-71

[6] WANG Sumin. On the Influence of Prominence, Feedback and Attention on the Output Capability of Second Language. Journal of Nanjing University of Aeronautics and Astronautics [J]. 2013.04:66-70 